\title{
Os Vínculos Organizacionais na Percepção de \\ Os Vínculos Organizacionais na Percepção de
Gestores: Comprometimento, Entrincheiramento e Consentimento
}

\author{
The Organisational Ties in the Perception of the Management: Commitment, \\ Entrenchment and Consent
} Entrenchment and Consent

\author{
(a)
}

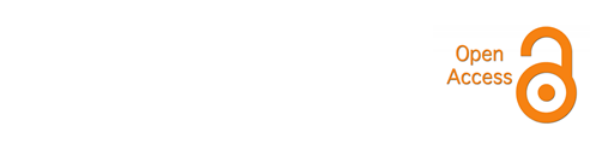

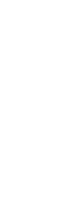

\author{
Gean Carlos Tomazzoni ${ }^{1,2}$ \\ Vânia Medianeira Flores Costa ${ }^{2}$ \\ Claudia Simone Antonello ${ }^{1}$ \\ Maria Beatriz Rodrigues ${ }^{1}$ 는
}

\section{RESUMO}

Objetivo: o objetivo deste estudo foi analisar a percepção sobre os vínculos de comprometimento, entrincheiramento e consentimento do trabalhador com a organização, explorando seus fatores distintivos e seus significados para gestores. Método: a pesquisa de abordagem qualitativa foi realizada com gestores de empresas do setor varejista, localizadas em shopping centers. Os dados foram coletados por meio da realização de dez entrevistas semiestruturadas e analisados com base na técnica de análise de conteúdo. Resultados: este trabalho empírico aponta que as percepções dos gestores não só sustentam a delimitação conceitual dos modelos de comprometimento à sua base afetiva, mas também revelaram a saliência diferencial de outros vínculos organizacionais, como o entrincheiramento e o consentimento. Os dados reforçam que os vínculos apresentam noções diferentes, que se operacionalizam em atitudes também distintas do indivíduo no trabalho. Conclusão: esses achados permitem compreender os possíveis influenciadores contextuais sobre o gerenciamento dos diferentes vínculos organizacionais, bem como seus resultados e impactos no desempenho do indivíduo no trabalho.

Palavras-chave: vínculos organizacionais; comprometimento; entrincheiramento; consentimento.

Classificação JEL: D23, J53, L8.

'Universidade Federal do Rio Grande do Sul, Escola de Administração, Porto Alegre, RS, Brasil.

${ }^{2}$ Universidade Federal de Santa Maria, Programa de Pós-Graduação em Administração, Santa Maria, RS, Brasil.

\section{ABSTRACT}

Objective: this study aimed to analyse the perception of the ties of commitment, entrenchment and consent of the worker with the organisation, exploring their distinctive factors and their meaning for the management. Method: a qualitative research was carried out with the management of companies of the retailing sector located in shopping malls. The data was gathered through ten semi-structured interviews and analysed using the content analysis technique. Results: this empirical work indicates that the managers' perceptions not only confirm the conceptual limitation of the commitment models to their affective basis, they also reveal the prominence of other organisational ties like entrenchment and consent. The data reinforce that these ties show different notions, which also operate in different attitudes of the individual at work. Conclusion: these findings allow to understand the possible contextual influences on managing the different organisational ties, as well as their outcomes and impact on the performance of the individual at work.

Keywords: organizational ties; commitment; entrenchment; consent.

\footnotetext{
Cite as: Tomazzoni, G. C., Costa, V. M. F., Antonello, C. S., \& Rodrigues, M. B. (2020). The organisational ties in the perception of the management: Commitment, entrenchment and consent. Revista de Administração Contemporânea, 24(3), 245-258. https://doi.org/10.1590/1982-7849rac2020190119
}

Editor-chefe: Wesley Mendes-Da-Silva (Fundação Getulio Vargas, EAESP, Brasil) Pareceristas: André Fischer (Universidade de São Paulo, Brasil) [C] Antônio Luiz Marques (Universidade de Barcelona, Espanha) 다

Recebido em: $21 / 03 / 2019$ Última versão recebida em: 17/09/2019 Aceite em: 27/09/2019

\# de revisores convidados até a decisão:

\begin{tabular}{|c|c|c|c|c|c|c|c|c|c|}
\hline & 1 & 2 & 3 & 4 & 5 & 6 & 7 & 8 & 9 \\
\hline $1^{a}$ rodada & $\stackrel{0}{2}$ & $\stackrel{\theta}{2}$ & & & & & & & \\
\hline $2^{a}$ rodada & (x) & $\stackrel{8}{6}$ & & & & & & & \\
\hline
\end{tabular}




\section{INTRODUÇÃO}

Desde a década de 1960 o comprometimento representa uma construção central no campo de estudos do comportamento organizacional e mantém esta relevância em tempos atuais (Wasti et al., 2016). A predominância de padrões de vínculos de comprometimento tem sido associada com comportamentos desejáveis e positivos do trabalhador (Pinho, Bastos, \& Rowe, 2015a). Apesar da natureza dinâmica das relações de trabalho que marcam o século XXI, as organizações precisam de uma força de trabalho comprometida e a maioria das pessoas quer se comprometer com algo (Klein, 2016).

No nível organizacional, ter uma força de trabalho comprometida está associada com maiores níveis de desempenho, margens de lucro e satisfação dos clientes (Cameron, Bright, \& Caza, 2004; Harter, Schmidt, Asplund, Killham, \& Agrawal, 2010; Heavey, Holwerda, \& Hausknecht, 2013). Acerca dos benefícios individuais do comprometimento, Gao-Urhahn, Biemann e Jaros (2016) constataram que trabalhadores com maior comprometimento provavelmente obterão níveis mais altos de renda.

A pluralidade de estudos sobre o comprometimento abrange aspectos conceituais e de mensuração que, apesar da longa trajetória de pesquisas, ainda representam desafios, tanto no contexto nacional, como no contexto internacional, revelando uma agenda de pesquisa que se encontra distante de ser esgotada. A imprecisão que envolve o comprometimento organizacional está relacionada, principalmente, com a ampliação excessiva do seu alcance conceitual e dimensional (Rodrigues, Bastos, \& Moscon, 2019).

Os diferentes conceitos que definem o comprometimento têm como ponto em comum a noção de estado psicológico que caracteriza a relação do indivíduo com a organização (Bastos, 1993). Porém, essa definição traz consigo problemas conceituais e limites pouco claros (Balsan, Bastos, Fossa, Lima, Lopes, \& Costa, 2015). O avanço das lentes teóricas sobre as relações estabelecidas entre o indivíduo e a organização, intensificado pelo debate sobre a natureza dimensional do comprometimento, possibilitou a descoberta de outros tipos de vínculos, distintos do comprometimento.

A introdução dos vínculos de entrincheiramento e consentimento organizacionais no campo de estudos do comportamento organizacional, realizada pelos trabalhos de Rodrigues (2009) e Silva (2009), sustenta que a noção de estar ou não comprometido é insuficiente para caracterizar a ligação do trabalhador com a organização. Segundo Balsan, Lopes, Alvez, Vizzotto e Costa (2016) o desenvolvimento desses novos construtos inaugura uma agenda de pesquisa centrada na diferenciação dos vínculos organizacionais, considerando que ao longo da vida o indivíduo desenvolve diversas relações com pessoas, grupos e organizações.

Sendo o comprometimento um tipo particular de vínculo psicológico, Klein, Molloy e Brinsfield (2012) reconhecem que outros vínculos também são importantes e, em determinados contextos, podem ser mais apropriados e alinhados com os objetivos da organização. Desse modo, os autores defendem a necessidade de trabalhos que almejam compreender outros tipos de ligações psicológicas e, idealmente, entender e prever quais tipos são mais desejáveis em determinado contexto.

Apesar do potencial explicativo do modelo de comprometimento afetivo (Bastos \& Aguiar, 2015; Klein \& Park, 2016; Rodrigues et al., 2019) e os avanços obtidos com a introdução dos construtos do entrincheiramento (Rodrigues, 2009; Rodrigues \& Bastos, 2012) e do consentimento (Silva, 2009; Silva \& Bastos, 2010), poucos estudos investigaram a perspectiva dos gestores sobre como esses vínculos se assemelham e se diferenciam em seus correlatos, antecedentes e consequentes. Baseado nas lacunas mencionadas, pretende-se com este estudo avançar no campo da teoria e empiricamente ao pesquisar o setor varejista, especificamente shopping centers, atingindo larga variedade de organizações, o que possibilita compreender como diferentes vínculos se constituem e se relacionam no contexto de cada organização pesquisada.

Assim, espera-se que os vínculos organizacionais atuem como influenciadores do comportamento do indivíduo no trabalho, bem como, essa relação possa ser mais intensa dependendo das combinações de padrões de vínculos que são desenvolvidas. Diante do exposto, este estudo tem por objetivo analisar a percepção sobre os vínculos de comprometimento, entrincheiramento e consentimento do trabalhador com a organização, explorando seus fatores distintivos e seus significados para gestores.

Dentro deste escopo, apresentam-se as implicações tanto teóricas como práticas. Por meio de implicações teóricas, este estudo relata evidências empíricas consistentes para sustentar a delimitação do conceito de comprometimento organizacional, minimizando a redundância conceitual e os problemas empíricos apontados pelos estudos apoiados no modelo tridimensional (Meyer \& Allen, 1991). Além disso, ao explorar a percepção de gestores brasileiros sobre a natureza distintiva dos diferentes vínculos organizacionais, se enfatiza a importância de não perder de vista os cuidados necessários ao aplicar modelos conceituais globais, atendendo ao que Wasti et al. (2016) explicam como influências culturais que podem alterar significativamente conceitos e medidas de vinculação ao trabalho. 
Quanto às implicações práticas, este estudo fornece informações que podem auxiliar no desenvolvimento de estratégias organizacionais direcionadas para processos de gerenciamento dos vínculos. Assim, ao compreender como a combinação de padrões de vínculos gera comportamentos desejáveis e positivos do trabalhador, é possível identificar padrões apropriados e alinhados com metas e comportamentos priorizados no enfrentamento dos desafios organizacionais. Por fim, ao ter como campo de pesquisa empresas do setor varejista, este estudo apresenta novas evidências que contribuem para uma compreensão mais apurada do contexto de trabalho desse setor, dando ênfase à multiplicidade de realidades organizacionais, que caracterizam os diferentes empreendimentos que integram o espaço de um shopping center.

Vínculos organizacionais: comprometimento, entrincheiramento e consentimento

O comprometimento organizacional é frequentemente definido como ligação, vínculo ou apego do indivíduo com a organização (Maia, Bastos, $\&$ Solinger, 2016). Os primeiros estudos sobre o tema foram consolidados por Mowday, Porter e Steers (1982), pioneiros na introdução do conceito, bem como da primeira medida de comprometimento organizacional na literatura. Para esses autores, o comprometimento representa a forte relação entre o indivíduo e a organização, sendo operacionalizado no esforço do trabalhador em prol da organização, pela crença e aceitação dos valores e objetivos organizacionais e pelo desejo em permanecer.

No modelo tridimensional proposto por Meyer e Allen (1991), o comprometimento é definido a partir de três bases que explicam a ligação do indivíduo com a organização. A base afetiva representa o desejo do indivíduo querer permanecer na organização por um sentimento de apego efetivo, que destaca a natureza emocional do vínculo entre a pessoa e a organização (Meyer \& Allen, 1991). A base normativa representa a vinculação por obrigação, em que o indivíduo se sente moralmente obrigado a permanecer (Meyer \& Allen, 1991). A base instrumental representa a conscientização de custos, em que o indivíduo percebe seus investimentos específicos na organização e não tem alternativas para mudar para outro lugar, caracterizando o vínculo organizacional contínuo ou instrumental (Meyer \& Allen, 1991).

A partir da introdução e ampla aceitação do modelo tridimensional de Meyer e Allen (1991), o comprometimento foi estudado com lentes de diferentes focos, bases e abordagens teóricas, na tentativa de melhor explicar seu desenvolvimento, seus antecedentes e consequentes, sendo um dos temas mais explorados pela literatura da área do comportamento organizacional (Pinho, Bastos, \&
Rowe, 2015b). Embora haja predominância desse modelo nas pesquisas nacionais e internacionais, a estrutura tridimensional está longe de representar um consenso entre pesquisadores, principalmente no que se refere às bases instrumental e normativa (Balsan et al., 2015).

Do debate sobre a dimensionalidade do comprometimento (Allen, 2016; Klein \& Park, 2016) e da emergente discussão acerca de como múltiplos comprometimentos se constituem e coexistem (Rossenberg et al., 2018), nos diferentes contextos organizacionais (Wasti et al., 2016), surge a sustentação de que o vínculo de natureza afetiva se diferencia fortemente dos vínculos instrumental e normativo. Nessa linha de raciocínio, os estudos de Rodrigues (2009) e Silva (2009) questionam se a noção de comprometimento integra à permanência do indivíduo por necessidade e por obrigação. Emerge, assim, a necessidade de tratá-los como fenômenos que não podem ser denominados comprometimento, dando origem a dois novos construtos, o entrincheiramento (Rodrigues, 2009; Rodrigues \& Bastos, 2012) e o consentimento (Silva, 2009; Silva \& Bastos, 2010).

Para explorar a complexidade do fenômeno, assume-se neste artigo o comprometimento como vínculo de natureza afetiva, considerando que essa base é conceitualmente menos controversa (Rodrigues et al., 2019) e associada mais fortemente com comportamentos desejáveis no trabalho (Pinho et al., 2015a). Ainda, argumenta-se que os vínculos de continuação e normativo devam ser explorados como fenômenos distintos do comprometimento, denominados entrincheiramento e consentimento, respectivamente.

O entrincheiramento é tratado inicialmente nos estudos de carreiras, introduzido para diferenciar o comprometimento com a carreira da tendência do indivíduo continuar em uma mesma ocupação, devido aos investimentos realizados, custos emocionais a serem dispendidos, mudança de ocupação e percepção limitada de caminhos alternativos fora do campo de atuação profissional (Carson \& Bedeian, 1994). No contexto organizacional, o entrincheiramento é definido como a tendência do indivíduo em permanecer na organização, devido aos investimentos e custos associados à sua saída e à percepção de limitações de alternativas no mercado de trabalho. O indivíduo entrincheirado se sente preso por não conseguir visualizar alternativas que o sustente de acordo com suas necessidades e expectativas (Rodrigues, 2009; Rodrigues \& Bastos, 2012).

Rodrigues (2009) propõe a adaptação do conceito de entrincheiramento com a carreira para o contexto das organizações, fundamentada nas pesquisas do comprometimento instrumental e na teoria de side bets de Becker (1960). Os side bets correspondem às trocas laterais entre indivíduo e organização, que 
fazem com que o trabalhador busque comportar-se de determinada maneira devido aos custos associados à sua saída (Becker, 1960). A dimensionalidade do entrincheiramento foi desenvolvida a partir do entendimento dos motivos pelos quais o trabalhador pode se sentir preso à organização: ajustamentos à posição social e arranjos burocráticos impessoais - provenientes da teoria de side bets proposta por Becker (1960) - e limitação de alternativas (Rodrigues, 2009).

A dimensão ajustamento à posição social representa a necessidade do indivíduo preservar as adequações que foram realizadas para adaptação à organização, como treinamentos, tempo para conhecer os processos organizacionais e atribuições da função, redes de relacionamentos, entre outros aspectos que contribuíram para seu ajuste e reconhecimento na organização (Rodrigues \& Bastos, 2012). Rodrigues e Bastos (2015) complementam que essa dimensão representa os investimentos do indivíduo e da organização nas condições necessárias para o bom desempenho de determinada atividade e adaptação do trabalhador à posição em que se encontra.

A dimensão arranjos burocráticos impessoais é definida pela estabilidade e ganhos financeiros que seriam perdidos pelo trabalhador caso deixasse a organização, como férias, feriados pagos, participação nos lucros, remuneração variável, benefícios de assistência médica, odontológica, previdência privada, aposentadoria, entre outros (Rodrigues \& Bastos, 2012). Rodrigues (2009) ressalta que as recompensas extrínsecas ou retornos materiais obtidos da organização, que o indivíduo não arrisca perder, desenvolvem sentimentos de estabilidade e proteção, que estão subjacentes ao entrincheiramento.

A dimensão limitações de alternativas é caracterizada pela percepção do indivíduo sobre a restrição no mercado de trabalho, ocorrida por visualizar ressalvas de mercado ou por acreditar que seu perfil profissional não teria aceitação em outra organização (Rodrigues \& Bastos, 2012). A percepção de pouca ou nenhuma alternativa representa um fator decisivo para que o indivíduo se sinta preso à organização. Segundo Rodrigues e Bastos (2012), essa noção atravessa todas as dimensões do entrincheiramento organizacional, com percepção de limitação intrínseca. Entretanto, a dimensão limitação de alternativas também traz percepção de limitação extrínseca, relativa à análise das opções disponíveis no mercado.

O consentimento organizacional encontra na literatura da psicologia social e sociologia seus pilares teóricos, caracterizado pelo vínculo entre o indivíduo e a organização, estabelecido a partir de uma perspectiva que, descartando elementos afetivos, enfatiza as relações de controle e autoridade que induzem o trabalhador a obedecer ou cumprir seu papel de subordinado (Pinho et al., 2015a). O vínculo de consentimento organizacional pressupõe que o trabalhador consinta com as demandas organizacionais, acate integramente as ordens estabelecidas e não se considere responsável por nenhuma consequência, principalmente negativa, que possa advir de suas ações (Silva \& Bastos, 2010).

Assim, o consentimento organizacional é entendido por Silva e Bastos (2015) como a tendência do indivíduo em obedecer às demandas da empresa, definidas por seus superiores, acreditando que o cumprimento das ordens e normas se deva às relações de poder e autoridade que se configuram entre o subordinado e o superior, bem como pela ideia de que a chefia saiba o que deva ser feito. Nesse conceito, Silva e Bastos (2015) restringem o consentimento à noção de obediência cega, excluindo a noção de aceitação íntima do trabalhador, inicialmente tratada como dimensão do consentimento (Silva, 2009; Silva \& Bastos, 2010). Assim, o vínculo de consentimento, na perspectiva de Silva e Bastos (2015), é conceituado como a tendência do indivíduo ao cumprimento automático da ordem, sem envolver avaliação ao seu respeito e sem compreensão acerca de seu significado.

\section{PROCEDIMENTOS METODOLÓGICOS}

Este trabalho se caracteriza como uma pesquisa de natureza exploratória, com o emprego de abordagem de métodos qualitativos. Participaram desta pesquisa organizações de natureza privada pertencentes ao setor varejista, localizadas nos shopping centers de Santa Maria, Rio Grande do Sul, Brasil. A escolha do campo de pesquisa se deu pela multiplicidade de realidades organizacionais, que caracterizam os diferentes empreendimentos que integram o espaço de um shopping center. A pesquisa contou com a participação dos empreendimentos dos quatro shopping centers da cidade, que atenderam aos critérios estabelecidos. As características comuns das organizações participantes são: (a) pertencer ao setor varejista; (b) manter suas atividades nos shopping centers participantes; (c) possuir equipe de trabalho com no mínimo 4 funcionários; e (d) consentir em participar deste estudo.

A seleção dos gestores entrevistados foi operacionalizada a partir dos resultados da fase preliminar da pesquisa, na qual foi aplicado um questionário acerca dos vínculos organizacionais de comprometimento (Bastos \& Aguiar, 2015), entrincheiramento (Rodrigues \& Bastos, 2015) e consentimento (Silva \& Bastos, 2015), com amostra de 260 trabalhadores. De posse dos resultados, foram selecionados para participar das entrevistas os gestores das organizações que apresentaram maiores níveis de vínculos organizacionais, mensurados por meio 
do cálculo da média geral da equipe de funcionários para os três construtos - comprometimento, entrincheiramento e consentimento.

Como critério para a quantidade de entrevistas utilizou-se a saturação das categorias que emergiram dos dados, de acordo com a orientação de Strauss e Corbin (2008). Seguindo tal pressuposto, foram realizadas dez entrevistas com os gestores das empresas participantes. Já a variação entre as empresas dos shopping centers pretendeu captar a visão ampla de campo e evitar que as particularidades de cada contexto organizacional se sobressaíssem nos resultados, conforme o critério triangulação de fontes proposto por Paiva, Leão e Mello (2011), que confere maior validade e confiabilidade na pesquisa qualitativa.

$\mathrm{O}$ roteiro de entrevista foi estruturado em quatro partes. Na primeira etapa, investigouse aspectos voltados para o mapeamento do perfil pessoal e ocupacional do entrevistado. $\mathrm{Na}$ segunda etapa foram exploradas as percepções dos gestores acerca das características do bom trabalhador para a organização. Na terceira etapa realizou-se a apresentação de 30 fichas, elaboradas por Pinho (2009), com frases que representavam noções e características de comprometimento, entrincheiramento e consentimento, sendo dez de cada vínculo organizacional. De posse das fichas, o entrevistado foi levado a escolher dez que representassem o bom trabalhador. Por fim, na terceira etapa, as fichas foram organizadas em três conjuntos, de acordo com o vínculo que representavam. Após a apresentação dos conjuntos de frases, o entrevistado foi questionado sobre como denominaria o trabalhador que apresentasse aquelas características.

As entrevistas foram gravadas e posteriormente transcritas, sendo a duração média de uma hora. As etapas da condução das entrevistas são detalhadas com a apresentação dos resultados. Os relatos dos entrevistados foram analisados por meio da técnica análise de conteúdo, com base em Bardin (2011), seguindo três fases: pré-análise, descrição analítica e interpretação inferencial. Na pré-análise, que corresponde ao processo de organização da análise (Bardin, 2011), as entrevistas foram transcritas, lidas e as falas foram alocadas dentro de cada proposição, que recebeu um tópico correspondente. Nessa fase, as transcrições foram enviadas para que cada entrevistado validasse o conteúdo da sua entrevista, para só então constituir a narrativa final.

$\mathrm{Na}$ fase de descrição analítica, ocorreu a exploração do material, sendo realizada a descrição analítica, com a contagem de palavras e unidades de análise (Bardin, 2011). Assim, com suporte do programa computacional NVIVO, os dados primários, advindos das entrevistas transcritas, foram selecionados e agrupados em duas categorias-chave: (a) antecedentes dos vínculos; e (b) consequentes dos vínculos. As principais categorias de análise foram definidas a priori, espelhando os modelos teóricos adotados, porém, mantendo abertura para outras possibilidades contidas nos relatos dos entrevistados.

A terceira fase, proposta por Bardin (2011), é a da interpretação inferencial, em que se busca a geração de inferências sobre o texto e as interpretações dos resultados. Dessa forma, interpretou-se o sentido de cada fala dos entrevistados, frente às categorias elencadas e às proposições estabelecidas. Nessa etapa, as transcrições das entrevistas foram confrontadas umas com as outras e com a teoria.

\section{ANÁLISE DE RESULTADOS E DISCUSSÃO}

Para garantir a confidencialidade e o anonimato, os gestores são tratados nesta pesquisa como G1 para o Gestor 1, G2 para o Gestor 2 e, assim, sucessivamente até G10, conforme descrito na Tabela 1.

Tabela 1. Caracterização dos sujeitos pesquisados.

\begin{tabular}{|c|c|c|c|c|c|c|}
\hline Gestor & Idade & Gênero & Escolaridade & Tempo na Empresa & Tempo no Cargo & $\mathrm{N}^{\circ}$ de Subordinados \\
\hline G1 & 55 anos & Masculino & Ensino Médio & 24 anos & 14 anos & 17 \\
\hline G2 & 42 anos & Feminino & Superior Completo & 5 anos & 1 ano & 5 \\
\hline G3 & 28 anos & Feminino & Superior Incompleto & 3 anos & 2 anos & 11 \\
\hline G4 & 46 anos & Masculino & Superior Completo & 8 anos & 6 anos & 13 \\
\hline G5 & 38 anos & Feminino & Superior Completo & 9 anos & 9 anos & 20 \\
\hline G6 & 54 anos & Masculino & Superior Completo & 20 anos & 15 anos & 19 \\
\hline G7 & 34 anos & Feminino & Superior Completo & 4 anos & 2 anos & 8 \\
\hline G8 & 37 anos & Feminino & Superior Completo & 7 anos & 3 anos & 8 \\
\hline G9 & 35 anos & Feminino & Ensino Médio & 14 anos & 4 anos & 12 \\
\hline G10 & 21 anos & Masculino & Ensino Médio & 3 anos & 2 anos & 6 \\
\hline
\end{tabular}

Nota. Descrição do perfil dos 10 gestores das empresas que apresentaram os maiores níveis de vínculos organizacionais, selecionados para a realização das entrevistas. Fonte: Elaborada pelos autores. 
Ao analisar as informações contidas na Tabela 1, percebe-se que a faixa etária dos gestores entrevistados varia entre 21 e 55 anos, sendo que 6 são do gênero feminino e 4 do gênero masculino. Quanto à escolaridade, constata-se que 6 gestores possuem ensino superior completo, sendo a maioria das formações na área de gestão e negócios. No que tange ao tempo de serviço na empresa, o tempo médio varia entre 4 e 24 anos, já o tempo no cargo de gerente varia entre 1 e 15 anos. O número de subordinados ou de profissionais sob supervisão do gestor varia entre 5 e 20 funcionários.
Na sequência apresentam-se as características identificadas pelos gestores entrevistados para conceituar o bom trabalhador. Esses dados são detalhados com base nas características que foram expostas pelos próprios sujeitos da pesquisa. Para categorizar as respostas, foram estruturadas três subcategorias de análise: a primeira concentra as características e atitudes de um bom trabalhador; a segunda aborda valores que esse trabalhador compartilha; e por fim, o desempenho que é atingido por esse trabalhador. A Figura 1 ilustra as noções atribuídas pelos gestores para conceituar o bom trabalhador.

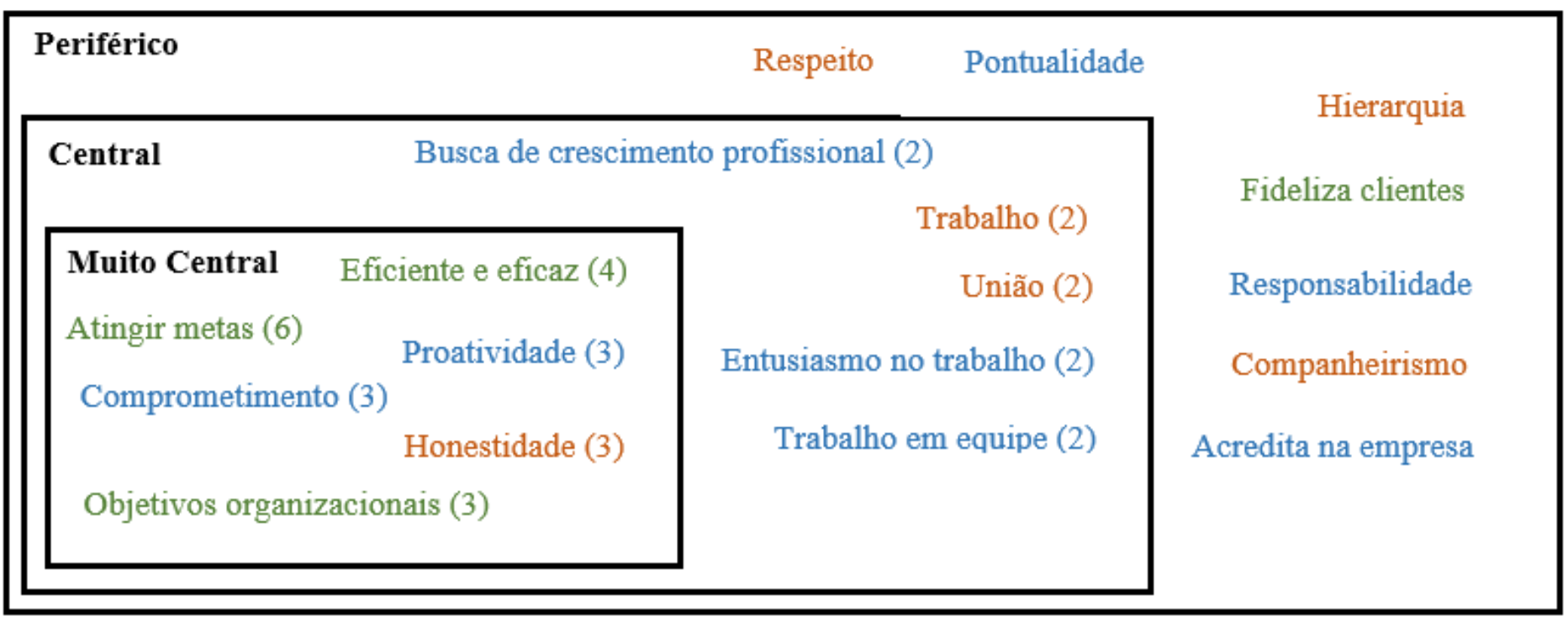

Figura 1. Percepções dos entrevistados sobre a noção de bom trabalhador.

Características e atitudes (azul); Desempenho (verde); Valores (laranja). Fonte: Elaborada pelos autores.

Ao analisar as informações ilustradas na Figura 1 , constata-se que a subcategoria características e atitudes obteve 8 citações referentes à definição de bom trabalhador. Observa-se que houve maior número de referência para os itens proatividade (3) e comprometimento (3). Ainda, destacam-se duas citações acerca da busca pelo crescimento profissional, capacidade de trabalho em equipe e entusiasmo no trabalho. Por fim, obtiveram uma única citação os itens pontualidade, crença na empresa e responsabilidade.

Com base nesses achados, para os gestores entrevistados, o bom trabalhador, além de ser comprometido, apresenta atitudes proativas diante das situações de trabalho vivenciadas na organização, expressadas nas demonstrações de preocupação com os resultados e objetivos da organização, em comportamentos de assiduidade e pontualidade, iniciativa para trazer soluções e no cuidado com a organização.

Nota-se que a noção de bom trabalhador se aproxima significativamente do conceito de comprometimento, corroborando outros estudos que exploraram o comprometimento organizacional a partir da percepção dos atores organizacionais (Pinho, 2009; Pinho et al., 2015a). Os resultados desses estudos indicaram que o comprometimento está atrelado às noções de engajamento, dedicação, zelo pelo setor em que trabalha, preocupação com o crescimento, zelo pela imagem, crescimento pessoal e profissional. Os discursos de cinco gestores revelam esse sentido positivo do conceito de bom trabalhador: 
"Comprometimento é a palavra certa ... eu acho que o comprometimento é fundamental. Hoje, o bom trabalhador ele tem que ter comprometimento com o que faz, além de entusiasmo, ele tem que ter empatia, ele tem que ter simpatia, e também pontualidade, essas que são pequenas coisas que fazem um bom profissional." (Entrevistado G1)

"Eu acho que a pessoa tem que estar feliz com o que ela está fazendo, gostar do que ela está fazendo, acreditar na empresa que ela trabalha e ter uma visão de crescimento. E quando eu falo em crescimento eu não digo só mudar de cargo ..., crescimento é saber que hoje tu melhorou um pouquinho em relação a ontem, em tudo." (Entrevistado G5)

"O bom colaborador corre atrás do que quer, tem bem definido em mente o que ele busca e o que ele deseja alcançar .... é aquele que corre atrás, que tem iniciativa própria, e que não depende de ninguém para dizer faz isso e faz aquilo. Ele tem que ter iniciativa própria para correr atrás do que ele quer." (Entrevistado G7)

"Uma pessoa que tem um bom convívio com os colegas, uma pessoa que chegue aqui e tenha o propósito de vestir a camiseta, de ir atrás das metas, e que o convívio seja leve, uma pessoa tranquila." (Entrevistado G8)

Destaca-se que os discursos dos gestores revelam que o conceito de bom trabalhador engloba itens que dizem respeito ao vínculo do comprometimento para diferentes focos organização, trabalho e grupo de trabalho - sendo que os conteúdos citados não agregaram aspectos dos construtos entrincheiramento e consentimento organizacionais. Esse achado corrobora Pinho (2009), que pesquisou três organizações de natureza distinta (uma privada, uma federal e uma municipal), e não identificou a presença de noções dos vínculos de entrincheiramento e consentimento na conceituação de bom trabalhador. Essa autora também observou que o trabalhador comprometido era visto como alguém que sente prazer em trabalhar na organização e acredita nos objetivos e valores organizacionais.

Referente à categoria valores que são compartilhados pelo bom trabalhador, a honestidade apresentou o maior número de citações (3), seguida da união (2), trabalho (2), hierarquia (1), respeito (1) e companheirismo (1). A partir disso, ressalta-se a importância de metas de valores, como exemplificam as apreciações dos entrevistados:

"Honestidade é algo que para dentro da empresa é fundamental. Tem que ser honesto em tudo, desde ser honesto de caráter, honesto com a tua equipe, honesto com as tuas opiniões, honesto com o teu cliente. Honestidade é fundamental aqui dentro." (Entrevistado G3)
"O valor principal do nosso negócio e pelo o que a gente lida aqui dentro, é honestidade. A pessoa tem que ter a minha confiança, a confiança da equipe, a confiança do cliente, afinal de contas a gente lida com valores da empresa e valores do cliente. Eu acho que a honestidade é o passo principal do nosso negócio." (Entrevistado G6)

"O respeito, uma boa convivência também, acho que a base de tudo é a questão do respeito, tu tendo o respeito tu tens o resto. E é o companheirismo, é muito o trabalho em equipe também porque aqui não adianta ser individual, tu tens que trabalhar em equipe, e eu acho que é isso." (Entrevistado G7)

A subcategoria desempenho reuniu citações que demostram o tipo de resultado/desempenho que é atingido pelo bom trabalhador. $\mathrm{O}$ atingimento das metas (6) foi o item mais mencionado pelos entrevistados, seguido da noção de eficiência e eficácia (4). Ainda, observam-se citações sobre o desempenho voltado para o alcance das metas globais da organização (3) e a fidelização de clientes (1).

Identificou-se que as falas acerca do desempenho se concentraram na área classificada como fundamental para a definição do bom trabalhador. Esse resultado demostra a importância atribuída ao desempenho, associado tanto com o desenvolvimento das tarefas laborais, quanto com os objetivos organizacionais. As falas dos gestores que apontam essas perspectivas são:

"Eu quero 50\% em dedicação em venda e quero $50 \%$ de dedicação dentro da empresa, porque não é só descer lá embaixo, atender o cliente e vender." (Entrevistado G2)

"O bom desempenho é aquele colaborador que realmente consegue alcançar a nossa meta, porque é muito difícil (...) então no dia a dia, como a gente está hoje, e com essa crise que tem, o bom colaborador é aquele que consegue alcançar a meta. É que tu tens vários meios aqui, só que isso depende de cada um usar ou não." (Entrevistado G7)

"Para nós, um importante indicador de desempenho é a fidelização de clientes. Se o funcionário consegue fidelizar clientes, com certeza ele está fazendo certo e isso é um bom desempenho." (Entrevistado G9)

"É um desempenho que contribui para o desempenho da organização como um todo, da loja, dos colegas e da gerência." (Entrevistado G10)

Percebe-se que houve referência tanto de aspectos técnicos, como o atingimento das metas, quanto de aspectos mais globais do desempenho no trabalho, como atingimento dos objetivos da organização. Entretanto, na percepção dos gestores, sobressaíram as questões técnicas, principalmente o alcance das metas de vendas. Pinho (2009) 
também identificou que a organização privada valoriza o foco no cliente como ponto importante na conceituação do bom trabalhador.

Diante dessas percepções, em primeira análise, o bom desempenho do indivíduo no trabalho está ligado ao atingimento das metas de vendas e, em segunda análise, emergem as questões mais amplas que envolvem suporte à organização no atingimento de metas globais. Assim, pode-se inferir que o bom trabalhador, na percepção dos gestores, apresenta características de vínculo afetivo, que geram comportamento como proatividade, iniciativa, compromisso com os objetivos da organização; compartilha valores que demostram preocupação com a coletividade, busca pelo sucesso e o respeito às normas e regras; e alcança bons indicadores de níveis de vendas, demostrando também preocupação com objetivos macro-organizacionais.

No segundo momento, no intuito de explorar com maior profundidade o conceito de bom trabalhador, os gestores receberam trinta fichas, sendo dez características de indivíduos comprometidos, dez características de indivíduos entrincheirados e dez características de indivíduos consentidos, conforme detalhado nos procedimentos metodológicos. Cada entrevistado selecionou dez fichas que, de acordo com a sua percepção, representavam as características do bom trabalhador. Na Figura 2 apresenta-se as características que foram selecionadas com maior número e ordem de frequência.

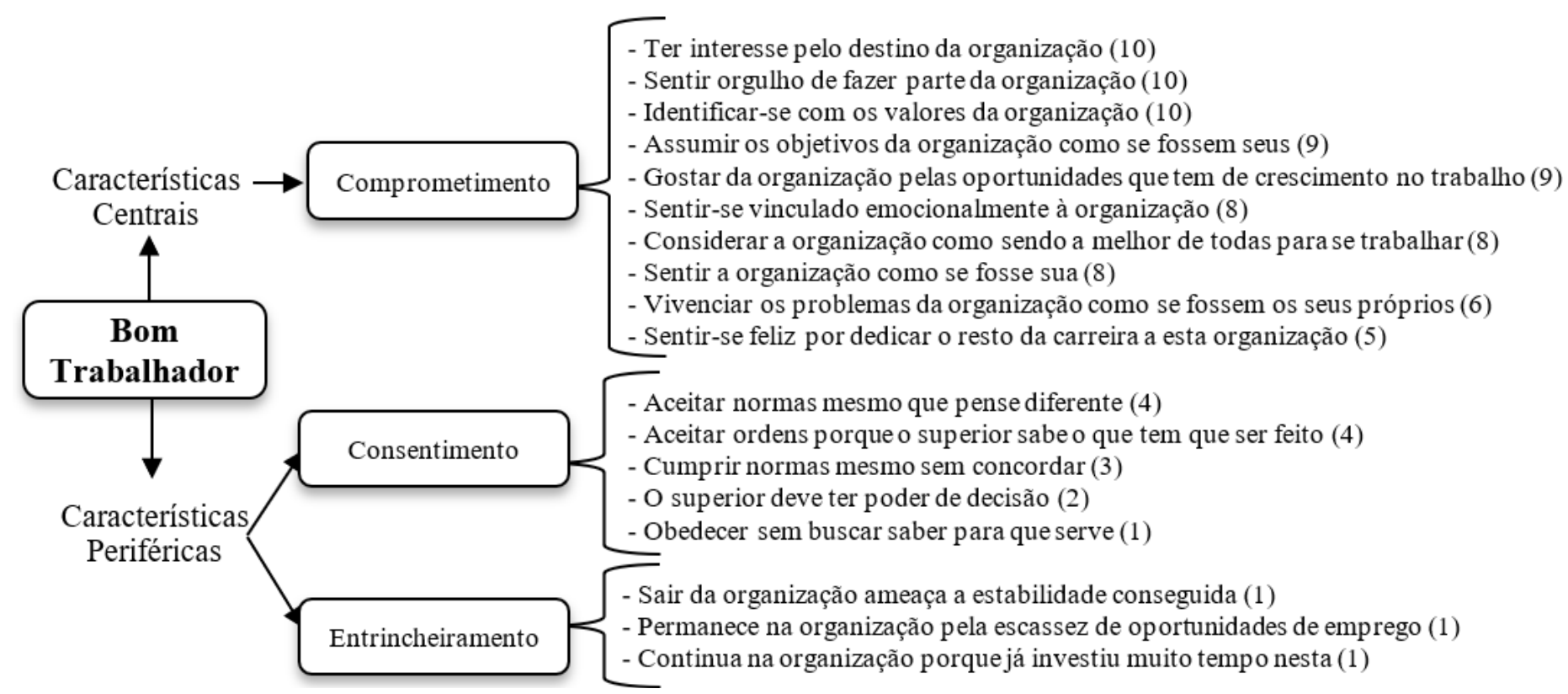

Figura 2. Características de vínculos que representam o bom trabalhador.

Noções dos vínculos organizacionais selecionados pelos entrevistados para definir o bom trabalhador. Os entrevistados puderam selecionar 10 entre as 30 noções apresentadas (10 para cada vínculo organizacional). Fonte: elaborada pelos autores.

Como pode-se visualizar na Figura 2, foram citadas 18 características, das trinta apresentadas. $\mathrm{O}$ conceito de um bom trabalhador expresso por esses gestores é predominantemente definido por noções que integram o comprometimento organizacional.

As sentenças que expressam interesse pelo destino da organização, orgulho por fazer parte e identificação com os valores foram os itens destacados como fundamentais para definir o bom trabalhador. O núcleo central de ideias que definem o bom trabalhador é constituído de conteúdos que determinam o comprometimento organizacional, sendo possível salientar o interesse pelo destino da organização, o orgulho em fazer parte e identificação com os valores organizacionais, como fatores fundamentais, referenciados por todos os gestores. Essas ideias que representam os sentimentos positivos diante da organização, caracterizam o bom trabalhador como o indivíduo que estabelece um padrão de vínculo predominantemente afetivo. As percepções corroboram estudo de Pinho, Bastos e Rowe (2015b), cuja ideia de trabalhador comprometido, na percepção 
dos gestores, reúne conteúdos, predominantemente, de noções afetivas.

As noções de consentimento organizacional também foram evocadas pelos entrevistados, porém, em menor grau de relevância. As ideias de que aceitar normas mesmo que pense diferente (4) e aceitar normas porque o superior sabe o que tem que ser feito (4), foram os itens com maior número de citações. Ainda emergiram os itens referentes ao cumprimento de normas mesmo sem concordar (3), a noção de que o superior deve ter poder de decisão (2) e que o trabalhador deve obedecer mesmo sem saber o porquê das suas ações (1).

As dimensões associadas teoricamente com o construto do entrincheiramento foram citadas para definir o bom trabalhador, embora tenham sido vistas com menor importância para essa definição, com apenas uma referência cada. As citações referemse às ideias de que a saída da organização ameaça a estabilidade do empregado, a permanência do indivíduo na organização se dá pela escassez de oportunidade no mercado e a continuidade na organização por já ter investido excessivo tempo nela.

Assim, os conteúdos periféricos evocados pelos gestores foram relacionados com noções dos vínculos de consentimento, voltadas para a perceptiva da obediência cega, que representa o cumprimento automático da ordem, sem envolver avaliação ao seu respeito, podendo até indicar que mesmo não havendo compreensão acerca do significado da tarefa, o trabalhador a realiza (Silva \& Bastos, 2010). Resultado semelhante foi obtido por Pinho (2009). Para essa autora, nas organizações de natureza privada, a presença de um chefe direto que tem poder de admitir ou demitir trabalhadores da equipe de trabalho, pode ser o fator que explica a adesão de noções do vínculo de obediência. Portanto, o não cumprimento de normas e regras ameaça o vínculo empregatício do trabalhador, pois pode ser considerado como comportamento desinteressado e negligente.

Diante desses resultados, constata-se que o vínculo desenvolvido pelo bom trabalhador é caracterizado pela natureza afetiva, com algumas referências ao vínculo normativo. Assim, essencialmente, o bom trabalhador congrega noções que apontam para o vínculo afetivo, no qual as expectativas diante da organização são valorosamente positivas e pressupõem o envolvimento construtivo (Pinho et al., 2015b).

A investigação do conceito de bom trabalhador e das características dos vínculos organizacionais de comprometimento, entrincheiramento e consentimento, que representam o bom trabalhador, permitiu compreender com maior profundidade as percepções dos entrevistados. Assim, dando continuidade, são apresentadas as denominações atribuídas pelos gestores para definir os diferentes vínculos organizacionais.

Para verificar os três conceitos de vínculos organizacionais, utilizou-se como estratégia a apresentação de trinta fichas com características que representavam ideias centrais de cada construto, sendo dez fichas para cada tipo de vínculo, organizadas em três colunas de frases: comprometimento, entrincheiramento e consentimento. Os entrevistados foram desafiados, com base na interpretação das fichas, a denominar quem era o trabalhador com aquele conjunto de características, questionando o nome que daria ao trabalhador que apresentasse tais características. A sistematização das respostas está ilustrada na Figura 3.
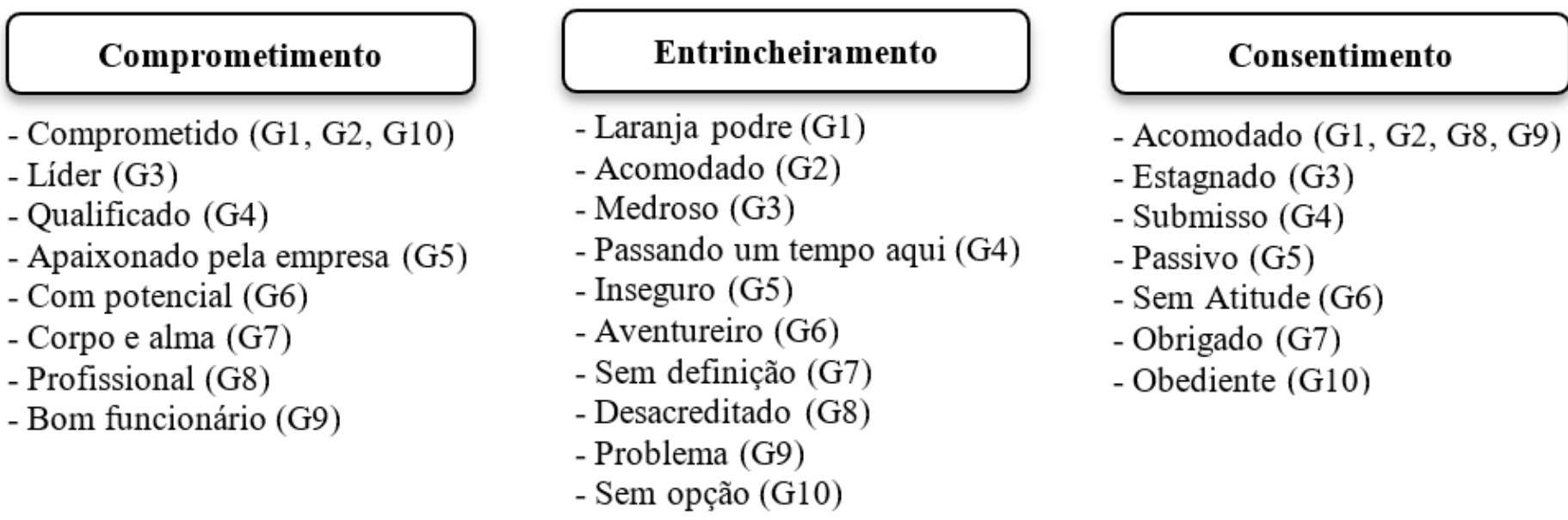

Figura 3. Denominações dos vínculos organizacionais na ótica dos gestores.

Denominações atribuídas pelos entrevistados para definir o trabalhador que apresentasse o conjunto de noções conceituais de comprometimento, entrincheiramento e consentimento. Fonte: elaborada pelos autores. 
Percebe-se que os gestores se reportaram de formas significativamente distintas para cada construto. O perfil de comprometimento foi mencionado como vínculo relacionado com aspectos valorosamente positivos, desejáveis tanto para o indivíduo, como para a organização. Nas palavras dos próprios entrevistados:

\begin{abstract}
"É o funcionário que veste a camisa, que se preocupa, que vem trabalhar com vontade, que a empresa cresça, que a empresa vá para frente, que quer crescer junto com a empresa, porque não existe uma empresa que não dá um horizonte para o funcionário, é o funcionário que tem que enxergar que a empresa crescendo automaticamente ele cresce junto." (Entrevistado G2)
\end{abstract}

\begin{abstract}
"Um líder, que provavelmente vai crescer, vai ter um futuro dentro da empresa, porque no momento que tu veste a camisa e tu dá o teu melhor, tu vive aquela empresa como se fosse tua, tu vira um líder." (Entrevistado G3)

"É um colaborador que entra de corpo e alma, porque tu pega todos os problemas da organização como se fossem teus, ele abraça e tenta fazer o melhor possível, tu te identifica com tudo o que acontece dentro dela, tanto os problemas quanto as coisas boas, então isso é um colaborador extremamente dedicado à organização." (Entrevistado G7)
\end{abstract}

Diferentemente das percepções acerca do conjunto de ideias que definem o comprometimento, os entrevistados apresentaram consenso em relação ao sentido negativo que o entrincheiramento carrega consigo. Foram elencadas denominações que remetem às perspectivas de insegurança, medo, acomodação e baixo rendimento. Essas perspectivas negativas são evidenciadas nas seguintes falas:

"De laranja podre. Eu acho que permanecer em uma instituição só por tá ali sem ter um objetivo ou sem querer estar ali, já vê que esse funcionário não vai ficar muito tempo contigo." (Entrevistado G1)

"É uma pessoa bem medrosa. É uma pessoa que não está feliz, mas que fica ali ... seria medrosa, desculpa, seria uma pessoa cômoda, acho [que] um adjetivo seria comodidade para aquela pessoa." (Entrevistado G3)

\footnotetext{
"Essa pessoa está passando o tempo comigo aqui, por vários motivos, mas não é aquilo que realmente está deixando a diferença na empresa. Ele pode estar passando o tempo aqui comigo ou por achar que oportunidade lá fora não existe, são pessoas que estão na empresa e que com certeza não estão dando o seu melhor aqui." (Entrevistado G4)
}

Da mesma forma que para o entrincheiramento, a noção de estar consentido revelou sentidos opostos aos do comprometimento, predominando ideias que não favorecem nem o crescimento dos indivíduos, nem das organizações. Os discursos dos entrevistados revelam essas ideias negativas associadas com o consentimento:

"Para mim é aquele trabalhador que tanto faz, tanto faz se vai fechar, tanto faz de estar vendendo, tanto faz se vai bater uma meta, tanto faz se tem uma meta ... é aquele que não faz diferença, não faz a diferença na empresa." (Entrevistado G2)

"Essa aqui é uma pessoa que não vai crescer. Claro, tem regras, tem que cumprir, mas também tu não tens que ser burro de carga até porque muitas vezes o questionamento faz com que a gente tenha boas ideias." (Entrevistado G3)

"Ele é considerado aquele funcionário que as organizações têm que ter, o braçal do dia a dia, mas que está meio que na zona de conforto, o que mandar vai fazer, não se pode esperar nada dele." (Entrevistado G6)

"Esse aqui está ali há anos e vai se aposentar por comodismo, pode estar insatisfeito, mas também não vai trocar, vai ficar ali até se aposentar ou até decidir mandar embora. Acho que o comodismo o deixa neste emprego." (Entrevistado G7)

As denominações dos gestores atribuídas às noções dos vínculos organizacionais reforçam as evidências de que os três construtos se reportam a fenômenos teóricos e empiricamente distintos. Os achados corroboram pesquisas recentes (Bastos \& Aguiar, 2015; Rodrigues \& Bastos, 2012; Silva \& Bastos, 2010), que delimitaram o comprometimento a sua vertente afetiva, associando-o com sentimento de orgulho, compromisso com a organização, engajamento e motivação do trabalhador.

Pinho, Bastos e Rowe (2015a) identificaram que noções de entrincheiramento e consentimento apresentam sentidos opostos em relação àqueles identificados para o comprometimento, corroborando os resultados encontrados. Para esses autores, itens relacionados à acomodação, à insegurança, ao medo de mudança, à luta pela sobrevivência são mais representativos da noção de estar entrincheirado. Já a noção de obediência na organização indicou subserviência e submissão, falta de análise crítica, acomodação, insatisfação e realização da atividade de forma mecânica (Pinho et al., 2015a).

Os achados permitem afirmar que os vínculos apresentam distintos fatores antecedentes e consequentes, corroborando perspectivas teóricas mais recentes (Bastos \& Aguiar, 2015; Pinho et al., 2015b; Rodrigues \& Bastos, 2015; Rodrigues et al., 2019; Silva \& Bastos, 2015). Ao reforçar as evidências de que se tratam de vínculos distintos, 
com antecedentes e consequentes também distintos, se sustenta a necessidade de compreensão de como múltiplos vínculos se configuram e funcionam de forma integrada, ou seja, como os múltiplos comprometimentos são substituídos, conflitantes, complementares e trabalham em sinergia com outros vínculos (Rossenberg et al., 2018). As evidências encontradas fortalecem a delimitação do conceito de comprometimento organizacional à sua base afetiva, superando o modelo tridimensional de Meyer e Allen (1991).

Por fim, partindo das denominações atribuídas pelo próprio entrevistado, foi solicitado que o gestor realizasse a avaliação da sua equipe de trabalho, para identificar a distribuição quantitativa de trabalhadores entre os vínculos de comprometimento, entrincheiramento e consentimento. As avalições dos gestores estão sistematizadas na Tabela 2.

Tabela 2. Avaliação da equipe de trabalho pelo gestor.

\begin{tabular}{|c|c|c|c|c|c|}
\hline \multirow{2}{*}{ Gestor } & \multicolumn{4}{|c|}{ Equipe de Profissionais Liderados } & \multirow{2}{*}{ Auto Percepção } \\
\hline & No Funcionários & Comprometidos & Entrincheirados & Consentidos & \\
\hline G1 & 17 & 17 & - & - & Comprometido \\
\hline G2 & 5 & 4 & - & 1 & Comprometido \\
\hline G3 & 11 & 2 & - & 9 & Comprometido \\
\hline G4 & 13 & 8 & 3 & 2 & Comprometido \\
\hline G5 & 20 & 14 & 2 & 4 & Comprometido \\
\hline G6 & 19 & 12 & 4 & 3 & Comprometido \\
\hline G7 & 8 & 7 & - & 1 & Comprometido \\
\hline G8 & 8 & 6 & 1 & 1 & Comprometido \\
\hline G9 & 12 & 10 & - & 2 & Comprometido \\
\hline G10 & 6 & 4 & 1 & 1 & Comprometido \\
\hline Total & 119 & 84 & 11 & 24 & Comprometidos \\
\hline
\end{tabular}

Nota. Avaliação dos entrevistados sobre a distribuição quantitativa das suas equipes de trabalho entre indivíduos comprometidos, entrincheirados e consentidos. Fonte: elaborada pelos autores.

Observa-se que os gestores acreditam que suas equipes de trabalho são predominantemente compostas por indivíduos comprometidos. Verificase que, nove dos dez gestores, indicaram a presença de pelo menos um profissional com noções de consentimento organizacional. O entrincheiramento, por sua vez, não obteve tanto destaque, mas foi referenciado por cinco gestores.

Outro dado que se destaca revela que dois gestores salientaram que os três vínculos podem se desenvolver simultaneamente, ou seja, um indivíduo que apresenta noções de comprometimento também pode estar entrincheirado e/ou consentido e viceversa. Esse achado é expresso nos discursos dos entrevistados G2 e G10:

"Hoje eu não tenho funcionários que são totalmente comprometidos ... digamos que eu vejo características dos três em quase todos, alguns tem mais de um ou de outro, mas possuem características dos três perfis ... eu tenho uma que, pela imaturidade, primeiro emprego, ela está em cima do muro, a gente sente que se tu deixar ela vai se acomodar." (Entrevistado G2)

"Digamos que não tem um vendedor que tenha uma característica de um perfil só, digamos que mistura muitas características. Na verdade, essas características estão presentes em praticamente todos os trabalhadores, combinadas de forma diferente." (Entrevistado G10)

As percepções dos gestores convergem com a ideia de que o indivíduo pode apresentar padrões de vínculos organizacionais que estabeleçam comprometimento, entrincheiramento e consentimento, simultaneamente, não excludentes entre si. Percebe-se que os trabalhadores vivenciam todos os vínculos em graus variados, ou seja, vínculos distintos coexistem no mesmo trabalhador, porém, com níveis e padrões diferenciados. 


\section{CONSIDERAÇÕES FINAIS}

Considerando que o objetivo deste estudo foi analisar a percepção sobre os vínculos de comprometimento, entrincheiramento e consentimento do trabalhador com a organização, explorando seus fatores distintivos e seus significados para gestores, pode-se desenvolver algumas ponderações.

Os conceitos atribuídos pelos gestores para denominar cada vínculo indicam sentido ativo para as características de estar comprometido, sentido pejorativo para estar entrincheirado e sentido passivo para estar consentido. Esses achados reforçam que os vínculos apresentam noções diferentes, que se operacionalizam em atitudes também distintas do indivíduo no trabalho. Além disso, identificou-se noções de vínculos não apenas com a organização, mas também com a carreira, grupos de trabalho e a liderança. Os resultados convergem para a ideia de que o indivíduo pode apresentar padrões de vínculos organizacionais que estabeleçam comprometimento, entrincheiramento e consentimento, simultaneamente, que não se excluem entre si.

As percepções dos gestores não somente sustentam a delimitação conceitual dos modelos de comprometimento à sua base afetiva, mas também revelaram a saliência diferencial de outros vínculos organizacionais, como o entrincheiramento e o consentimento. Assim, este trabalho cumpre o papel de apresentar evidências empíricas consistentes para sustentar os esforços de maior delimitação do conceito do comprometimento. Ao explorar as percepções dos gestores sobre as noções dos vínculos organizacionais, esta pesquisa traz contribuições importantes para delimitação conceitual do comprometimento e sua distinção com os novos vínculos que surgiram na literatura.

Verificou-se que os entrevistados atribuem menos peso às noções de permanência, quando o funcionário atinge altos níveis de desempenho no trabalho. Com base nesses achados, pode-se dizer que a noção de permanência embutida na definição dos vínculos organizacionais é considerada mais uma consequência do que uma condição para o desenvolvimento do vínculo organizacional. Desse modo, os resultados indicam que as organizações estão menos preocupadas com as razões pelas quais o funcionário permanece, uma vez que contribuições ativas são mais esperadas do que a continuidade passiva do trabalhador.
O conceito de comprometimento, como definido por Bastos e Aguiar (2015), parece abarcar noções que se diferenciam dos conceitos de entrincheiramento e consentimento. A análise da noção de bom trabalhador evidenciou que os gestores esperam trabalhadores engajados, envolvidos emocionalmente e que revelem comprometimento com a organização. Embora, por outro lado, o discurso dos gestores revele que, em determinados contextos, características do vínculo de consentimento possam ser necessários e alinhados com os objetivos da organização. Os gestores também esperam das equipes de trabalho o cumprimento de normas e de ordens, elementos do vínculo de obediência. Esse resultado sustenta novos olhares da literatura sobre os vínculos de entrincheiramento e consentimento, que embora não estejam associados com comportamentos proativos do trabalhador, podem ser considerados vínculos necessários e desejáveis em determinados contextos organizacionais.

Para pesquisas futuras, sugere-se a realização de estudos com abordagem longitudinal, que permitam acompanhar tanto o estabelecimento, quanto a manutenção dos vínculos do indivíduo com a organização. Para avanço neste campo de conhecimento, recomenda-se o desenvolvimento de estudos sobre os diferentes padrões de vínculos, combinando níveis distintos de comprometimento, entrincheiramento e consentimento, relacionandoos com modelos de políticas e práticas de gestão de pessoas, visando a compreensão mais profunda sobre o processo de gerenciamento desses vínculos.

Ao finalizar esta pesquisa, acredita-se que foram obtidas importantes contribuições para o meio científico da área de Administração, especialmente no que tange às temáticas do campo do comportamento organizacional. Teoricamente, por contribuir com o aumento de investigações sobre os vínculos de entrincheiramento e consentimento organizacionais, recentemente introduzidos na literatura a partir dos avanços do conhecimento sobre o comprometimento. A realização desta pesquisa em um contexto de múltiplas organizações, no caso empresas do setor varejista que atuam em shoppings centers, possibilitou a análise das especificidades do contexto e a observação de padrões que se repetiram em mais de uma organização participante. Por fim, este estudo não pode deixar de apontar seus limites. Destaca-se o fato de o estudo abordar aspectos comportamentais, os quais possuem caráter subjetivo e complexo e que dados transversais foram utilizados neste estudo. 


\section{REFERENCIAS}

Allen, N. J. (2016). Commitment as a multidimensional construct. In J. P. Meyer (Ed.), The handbook of employee commitment (pp. 28-42). Northampton: Edward Elgar Publishing.

Balsan, L. A. G., Bastos, A. V. B., Fossa, M. I. T., Lima, M. P., Lopes, L. F. D., \& Costa, V. M. F. (2015). Comprometimento e entrincheiramento organizacional: Explorando as relações entre os construtos. Revista de Administração da UFSM, 8(1), 235-248. http://dx.doi. org/10.5902/198346599942

Balsan, L. A. G., Lopes, L. F. D., Alves, J. N., Vizzotto, F. B., \& Costa, V. M. F. (2016). Impacto do treinamento, comprometimento e entrincheiramento organizacionais em servidores de uma universidade pública. Revista Gestão Universitária na América Latina, 9(1), 143-164. http://dx.doi.org/10.5007/19834535.2016v9n1p143

Bardin, L. (2011). Análise de conteúdo. Lisboa: Edições 70.

Bastos, A. V. B. (1993). Comprometimento organizacional: Um balanço dos resultados e desafios que cercam essa tradição de pesquisa. Revista de Administração de Empresas, 33(3), 52-64. http://dx.doi.org/10.1590/ S0034-75901993000300005

Bastos, A. V. B., \& Aguiar, C. V. N. (2015). Comprometimento organizacional. In K. Puente-Palacios, \& A. L. A. Peixoto (Orgs.), Ferramentas de diagnóstico para organizações e trabalho: Um olhar a partir da psicologia (pp.78-91). Porto Alegre: Artmed.

Becker, H. S. (1960). Notes on the concept of commitment. American Journal of Sociology, 66(1), 32-40. https:// doi.org/10.1086/222820

Cameron, K. S., Bright, D., \& Caza, A. (2004). Exploring the relationships between organizational virtuousness and performance. American Behavioral Scientist, 47(6), 766790. https://doi.org/10.1177/0002764203260209

Carson, K. D., \& Bedeian, A. G. (1994). Career commitment: Construction of a measure and examination of its psychometric properties. Journal of Vocational Behavior, 44(3), 237-262. https://doi.org/10.1006/ jvbe.1994.1017

Gao-Urhahn, X., Biemann, T., \& Jaros, S. J. (2016). How affective commitment to the organization changes over time: A longitudinal analysis of the reciprocal relationships between affective organizational commitment and income. Journal of Organizational Behavior, 37(4), 515-536. https://doi.org/10.1002/job.2088

Harter, J. K., Schmidt, F. L., Asplund, J. W., Killham, E. A., \& Agrawal, S. (2010). Causal impact of employee work perceptions on the bottom line of organizations. Perspectives on Psychological Science, 5(4), 378-389. https://doi.org/10.1177/1745691610374589

Heavey, A. L., Holwerda, J. A., \& Hausknecht, J. P (2013). Causes and consequences of collective turnover: A metaanalytic review. Journal of Applied Psychology, 98(3), 412-453. https://doi.org/10.1037/a0032380
Klein, H. J. (2016). Commitment in organizational contexts: Introduction to the special issue. Journal of Organizational Behavior, 37(4), 489-493. https://doi. org/10.1002/job.2103

Klein, H. J., Molloy, J. C., \& Brinsfield, C. T. (2012). Reconceptualizing workplace commitment to redress a stretched construct: Revisiting assumptions and removing confounds. Academy of Management Review, 37(1), 130-151. https://doi.org/10.5465/arma.2010.0018

Klein, H. J., \& Park, H. (2016). Commitment as a unidimensional construct. In J. P. Meyer (Ed.), The handbook of employee commitment (pp. 15-27). Northampton: Edward Elgar Publishing.

Maia, L. G., Bastos, A. V. B., \& Solinger, O. N. (2016). Which factors make the difference for explaining growth in newcomer organizational commitment? A latent growth modeling approach. Journal of Organizational Behavior, 37(4), 537-557. https://doi.org/10.1002/job.2096

Meyer, J. P., \& Allen, N. J. (1991). A three-component conceptualization of organizational commitment. Human Resource Management Review, 1(1), 61-89. https://doi.org/10.1016/1053-4822(91)90011-Z

Mowday, R. T., Porter, L. W., \& Steers, R. M. (1982). Employeeorganization linkages: The psychology of commitment, absenteism and turnover. New York: Academic Press.

Paiva, F. G. de, Jr., Leão, A. L. M. de S., \& Mello, S. C. B. de (2011). Validade e confiabilidade na pesquisa qualitativa em administração. Revista de Ciências da Administração, 13(31), 190-209. https://doi.org/10.5007/21758077.2011v13n31p190

Pinho, A. P. M. (2009). Comprometimento, entrincheiramento e consentimento organizacionais: Uma análise destes vínculos, entre gestores e trabalhadores, de diferentes organizações (Tese de Doutorado). Universidade Federal da Bahia, Salvador, BA, Brasil. Retrieved from http:// repositorio.ufba.br/ri/handle/ri/24580

Pinho, A. P. M., Bastos, A. V. B., \& Rowe, D. E. O. (2015b). Diferentes vínculos indivíduo-organização: Explorando seus significados entre gestores. Revista de Administração Contemporânea, 19(spe3), 288-304. https://doi. org/10.1590/1982-7849rac20151635

Pinho, A. P. M., Bastos, A. V. B., \& Rowe, D. E. O. (2015a). Diferentes vínculos organizacionais: Explorando concepções, fatores organizacionais antecedentes e práticas de gestão. Organizações \& Sociedade, 22(75), 659-680. https://doi.org/10.1590/1984-9237510

Rodrigues, A. C. de A. (2009). Do comprometimento de continuação ao entrincheiramento organizacional: $O$ percurso de validação da escala e análise da sobreposição entre os construtos (Dissertação de Mestrado). Universidade Federal da Bahia, Salvador, BA, Brasil. Retrieved from https://pospsi.ufba.br/sites/pospsi.ufba.br/files/ana_ carolina_rodrigues.pdf

Rodrigues, A. C. de A., \& Bastos, A. V. B. (2012). Organizational entrenchment: Scale development and validation. Psicologia: Reflexão e Crítica, 25(4), 688-700. https://doi. org/10.1590/S0102-79722012000400008

Rodrigues, A. C. de A., \& Bastos, A. V. B. (2015). Entrincheiramento organizacional. In K. Puente-Palacios, \& A. L. A. Peixoto 
(Orgs.), Ferramentas de diagnóstico para organizações e trabalho: Um olhar a partir da psicologia (pp.107121). Porto Alegre: Artmed.

Rodrigues, A. C. de A., Bastos, A. V. B., \& Moscon, D. C. B. (2019). Delimiting the concept of organizational commitment: Empirical evidence of the overlap between the entrenchment and the continuance mindset. Organizações \& Sociedade, 26(89), 338-358. https://doi.org/10.1590/1984-9260897

Rossenberg, Y. G. T. van, Klein, H. J., Asplund, K., Bentein, K., Breitsohl, H., Cohen, A., Cross, D., Rodrigues, A. C. de A., Duflot, V., Kilroy, S., Ali, N., Rapti, A., Ruhle, S., Solinger, O., Swart, J., \& Yalabik, Z. Y. (2018). The future of workplace commitment: Key questions and directions. European Journal of Work and Organizational Psychology, 27(2), 153-167. https:// doi.org/10.1080/1359432X.2018.1443914

Silva, E. E. da C. (2009). Consentimento organizacional: Uma proposta de medida do construto (Dissertação de Mestrado). Universidade Federal da Bahia, Salvador, BA, Brasil. Retrieved from https://pospsi.ufba.br/ sites/pospsi.ufba.br/files/eliana_edington.pdf

Silva, E. E. da C., \& Bastos, A. V. B. (2010). A escala de

\section{Autores}

\section{Gean Carlos Tomazzoni*}

Rua Washington Luiz, $n^{\circ}$ 855, Centro Histórico, 90010-460, Porto Alegre, RS, Brasil.

E-mail: gean.tomazzoni@hotmail.com

๑ https://orcid.org/0000-0003-4736-009X

\section{Vânia Medianeira Flores Costa}

Av. Roraima, $\mathrm{n}^{0}$ 1000, Prédio 74C, Cidade Universitária, 97105-900, Santa Maria, RS, Brasil.

E-mail: vania.costa@ufsm.br

๑ https://orcid.org/0000-0002-6099-820X

\section{Claudia Simone Antonello}

Rua Washington Luiz, $n^{\circ}$ 855, Centro Histórico, 90010-460, Porto Alegre, RS, Brasil.

E-mail: claudia.antonello@ufrgs.br

๑ https://orcid.org/0000-0001-9654-5125

\section{Maria Beatriz Rodrigues}

Rua Washington Luiz, n 855, Centro Histórico, 90010-460, Porto Alegre, RS, Brasil.

E-mail: beatriz.rodrigues@ufrgs.br

(- https://orcid.org/0000-0003-3529-9009

* Autor Correspondente

\section{Contribuições dos Autores}

$1^{\circ}$ autor: Conceituação (Liderança); Curadoria de dados (Liderança); Análise formal (Liderança); Aquisição de financiamento (Suporte); Investigação (Liderança); Metodologia (Igual); Administração de projeto (Igual); Software (Liderança); Supervisão (Igual); Validação (Igual); Escrita - rascunho original (Liderança); Escrita - revisão e edição (Igual). consentimento organizacional: Construção e evidências de sua validade. Revista Psicologia: Organizações e Trabalho, 10(1), 7-22. Retrieved from https://periodicos.ufsc.br/index.php/rpot/article/ view/17273

Silva, E. E. da C., \& Bastos, A. V. B. (2015). Consentimento organizacional. In K. Puente-Palacios, \& A. L. A. Peixoto (Orgs.), Ferramentas de diagnóstico para organizações e trabalho: Um olhar a partir da psicologia (pp. 92106). Porto Alegre: Artmed.

Strauss, A., \& Corbin, J. (2008). Pesquisa qualitativa: Técnicas e procedimentos para o desenvolvimento de teoria fundamentada. Porto Alegre: Artmed.

Wasti, S. A., Peterson, M. F., Breitsohl, H., Cohen, A., Jørgensen, F., Rodrigues, A. C. de A., Weng, Q., \& Xu, X. (2016) Location, location, location: Contextualizing workplace commitment. Journal of Organizational Behavior, 37(4), 613-632. https://doi.org/10.1002/job.2094

$2^{\mathbf{a}}$ autora: Conceituação (Igual); Curadoria de dados (Suporte); Análise formal (Igual); Aquisição de financiamento (Liderança); Investigação (Igual); Metodologia (Suporte); Administração de projeto (Liderança); Software (Suporte); Supervisão (Liderança); Validação (Igual); Escrita - rascunho original (Igual); Escrita - revisão e edição (Igual).

$3^{\mathbf{a}}$ autora: Conceituação (Igual); Análise formal (Igual); Investigação (Igual); Metodologia (Igual); Administração de projeto (Suporte); Supervisão (Suporte); Validação (Igual); Escrita - rascunho original (Igual); Escrita - revisão e edição (Liderança).

$4^{\mathbf{a}}$ autora: Conceituação (Igual); Análise formal (Igual); Investigação (Igual); Metodologia (Igual); Administração de projeto (Suporte); Supervisão (Suporte); Validação (Igual); Escrita - rascunho original (Igual); Escrita - revisão e edição (Liderança).

Financiamento

O presente trabalho foi realizado com o apoio da Coordenação de Aperfeiçoamento de Pessoal de Nível Superior - Brasil (CAPES) - Código de Financiamento 001.

Conflito de Interesses

Os autores informaram que não há conflito de interesses.

Direitos Autorais

A RAC detém os direitos autorais deste conteúdo.

Verificação de Plágio

A RAC mantém a prática de submeter todos os documentos aprovados para publicação à verificação de plágio, mediante o emprego de ferramentas específicas, e.g.: iThenticate.

\section{Método de Revisão por Pares}

Este conteúdo foi avaliado utilizando o processo de revisão por pares duplo-cego (double-blind peer-review). A divulgação das informações dos pareceristas constantes na primeira página é feita somente após a conclusão do processo avaliativo, e com o consentimento voluntário dos respectivos pareceristas. 